\title{
Goserelin Regimen
}

National Cancer Institute

\section{Source}

National Cancer Institute. Goserelin Regimen. NCI Thesaurus. Code C160044.

A hormone therapy regimen consisting of goserelin that may be used in the treatment of breast and prostate cancers. 